\title{
Commented Madness Project: Works about the Academical Vision of Concepts in Psychiatry and Mental Health
}

\section{Cely Carolyne Pontes Morcerf ${ }^{1 *}$, Rafael Rodrigues Matias ${ }^{2}$ and Andrea Regina dos Santos Murga da Rocha ${ }^{3}$}

${ }^{1}$ Department of Mental Health, University Unigranrio, Rio de Janeiro, Brazil

${ }^{2}$ Department of Psychiatry, University Unigranrio, Rio de Janeiro, Brazil

${ }^{3}$ Department of Medical Education, University Unigranrio, Rio de Janeiro, Brazil

*Corresponding author: Cely Carolyne Pontes Morcerf, Department of Mental Health, University Unigranrio, Rio de Janeiro, Brazil, Tel: +5521981681817; E-mail: cely_carol@hotmail.com

Received date: September 4, 2018; Accepted date: September 14, 2018; Published date: September 21, 2018

Copyright: (c) 2018. Pontes Morcerf CC, et al. This is an open-access article distributed under the terms of the Creative Commons Attribution License, which permits unrestricted use, distribution, and reproduction in any medium, provided the original author and source are credited.

Citation: Pontes Morcerf CC, Matias RR, Murga da Rocha AR (2018) Commented Madness Project: Works about the Academical Vision of Concepts in Psychiatry and Mental Health. J Contracept Stud Vol.3 No.3:22

\section{Abstract}

The present study is an experience report that analyzes the perception of the medical students of Unigranrio, Barra da Tijuca, regarding the performance of the psychiatrist, in the field of specialty practice in primary care and in the psychiatric emergency service, and in relation to the insertion of the non-teaching of medical education, as well as basic themes in mental health, highlighting the feelings about the contact and approach of the patient with mental disorders and self-perception of the medical student's mental health, allowing reflections on the problem of existing non-teaching doctor. It carried out an evaluation in order to bring contributions to mental health education, detecting the presence of erroneous concepts, stereotypes and perceptions related to the subject in the formation of the student, at the same time as it discussed the need of forms of intervention to overcome challenges that involve obstacles and methodologies of mental health teaching in the medical course. The project leads to reflections on teachers and students, the possibility of mobilization at improving the future formation of the doctor, in a view of the magnification and relevance of psychiatry teaching. The construction of the project made it possible to highlight a different perspective for insertion and expansion of mental health to medical students, and for analysis of the Psychiatric Reform process, as well as questions about the need for changes in the medical curriculum formation, about concepts, sensations, misconceptions, prejudices, fears and anxieties related to the care of the psychiatric patient.

Keywords: Mental health; Psychiatry; Medical education

\section{Introduction}

The perception of society in relation to the figure of the madman as an individual causing social disorder, with a mixture of fear and incomprehension of the reason for his behavior distinct from the normal range, led to the exclusion of patients suffering from psychic social conviviality, from the time of the Middle Ages, through the institutionalization of people diagnosed with mental disorders, with historical reports of expulsion of the crazy of cities, marking a process called "institutionalization of madness" [1].

Long-term psychiatric hospitals established themselves as an alternative to ward off people who manifested strange behaviors outside the normal range of the environment in which they lived, thus ensuring a better and greater control of these patients and a relief for the other members of the hospital. Society who did not know about psychopathology and other theories of mental disorders, leading to fear, stigma and the desire to live far from any manifestation of madness. In parallel to this, the subject lost his individuality and his personal characteristics, being the acts and behaviors attributed exclusively to mental illness, with exposure to institutional violence [1].

The exclusion resulting from a historical process of stigma of madness also stems from an association of mental illness with a concept of abnormality, linked to the breakdown of sociability, as something that needs to be rescued and modified to return to a situation of conventionally known social pattern, historically and socially as normal 3. From this idea, what makes a person with mental disorder different from the standard imposed by society, regardless of whether or not it is being accompanied by mental health service, is the subject of attention, fears and attention as social deviation, leading to labels and stigmas that indirectly exclude and compromise the quality of life, dignity and respect for the role of this patient as a citizen [2-4]. 
The Psychiatric Reform was established as a process of change to create ways to guarantee the rights of patients with mental disorders, which aim to modify relations with the idea of madness, insanity and mental disorder, and the creation of a welcoming environment, of exchange and solidarity. However, it is necessary first to mobilize efforts to transform the way of understanding madness, the figure of the madman and the manicomial model, in a stereotype-free and liberating way of thinking for the psychiatric patient's approach, approach and treatment in mental health care in a human and integral way $[5,6]$.

Machado and Pereira [7] carried out a study published in 2013 on the perception of health professionals, members of a Family Health Unit, on mental illness, identifying the reproduction of social prejudices regarding the approach and contact with patients with mental disorder and ideas biologists. This study indicated a need for a greater capacity of the health professional to deal with patients suffering from psychic suffering, transforming preformed ideas based on stigmas and common sense, even in a group of professionals with training in the health area. This phenomenon needs to be investigated in the genesis of the education and training of these health professional, identifying aspects necessary for a greater approach and intervention aimed at reducing the thoughts and practices of traditional psychiatry with a focus on medicalization of the disease and centralization of the psychiatrist and hospitalization as only relevant ways of treating this patient. Thus, medical education, and of health professionals in general, challenges by bringing to the fore practical and theoretical demands on a broad formation encompassing concepts beyond traditional formation, making possible a critical analysis of the historical-cultural context and the current conjuncture that involves the field of mental health [7-9].

The current economic model in Brazilian society, markedly excluding and unequal, is closely associated with the difficulties faced during the Psychiatric Reform. The deconstruction of a highly instilled mental health culture in the minds of students and health professionals is an arduous and complex task, but this should not limit the ongoing work of changing perceptions and empowerment based on joint discussions and reflections. The University plays a central role in the fight against the rooting of ideas of the traditional psychiatric asylum, since it is responsible for the formation of professionals directly responsible for the history and development of the Psychiatric Reform. We must fight against the withdrawal of contact with patients suffering from psychic suffering by enabling and opening spaces for debate and reflection within the medical training curriculum in order to deconstruct prejudices and misconceptions that feed the process of exclusion and rupture of the patient's social integration with mental disorder [10-12].

The changes in the care of patients with mental disorders and in the vision of psychiatry are closely related to a work of intervention and debate with the university, creating spaces for training, reflection and discussion on historical aspects and fundamental concepts in psychiatry, critically and intervention in the qualification of the health professional, in his general training. Therefore, medical schools have a fundamental role in the creation of projects for the transformation of reality that permeates the assistance and teaching of mental health in medical schools, promoting the training of actors engaged in the fight against the breakdown of mental health stigmas and prejudices and to the incentive of participation of the militant along with the process of transformation and break of asylum and traditional roots of psychiatry. Thus, the continuity of the reform process in the production of more social spaces of action and valuation of patients considered crazy, breaking institutional and prejudicial walls to review stigmatizing beliefs and values, is sought [13-15].

Having seen the lack of studies that involve mobilization, work with programming for the study of student perceptions and debates, critics in mental health literature have the job of reporting on the experience of an academic extension project initiated from of the discipline of Psychiatry and that was developed in a group of 150 students.

\section{Material and Methods}

It is a work of an applied, descriptive, qualitativequantitative nature, with a theoretical-empirical approach, with a bibliographical research using the Virtual Health Library $(\mathrm{VHL})$. This paper presents a literature review involving the theme of societal perception, with a focus on health professionals and students, in the face of the contact and care of the psychiatric patient, as well as the knowledge of nosological syndromes and diagnoses in psychiatry, approaches in mental health and the process of historical construction of the foundations of modern psychiatry and the evolution of mental health, from traditional psychiatry to the changes that have occurred with the Psychiatric Reform. The influence of the historical-cultural context and the achievements of the anti-psychiatric struggle in the development of modern psychiatry and in definitions of concepts in mental health and the impact of the persistence of old values, ideas and stereotypes in the approach, socialization and contact with the psychiatric patient. The descriptors used in Portuguese language were perception, psychiatry and mental health, with a balance of 588 scientific articles. Only articles of Portuguese, English and Spanish language were filtered, with a final balance of 551 articles, selecting 21 articles for the present work, from 1985 to 2016.

The databases consulted were SCIELO (Scientific Electronic Library Online), LILACS (Latin American and Caribbean Literature in Health Sciences), MEDLINE (Medical Literature Analysis and Retrieval System Online) and IBECS (Spanish Bibliographical Index of Health Sciences) for selection of articles.

\section{Extension Project Offices}

For the qualitative nature of the work, workshops were created with the students after the application of the questionnaire, with the signing of an authorization term for the use of testimonies, where discussions were started on 
basic concepts in mental health encompassing the topics of anti-manicomial fight, mental health in basic care, psychic examination, expansion of mental health in the medical curriculum, therapeutic residences, art therapy, Homecare Program, Medicalization, Compulsory Internment, Psychosocial Support Center and Mental Disorders, themes that were debated in a group approach and reflective. All authorized statements were disclosed without the identification of the participants, and letters were used to maintain the confidentiality of the information. The statements were recorded and later transcribed. The recordings will not be divulged, guaranteeing complete secrecy.

Evidenced perceptions and experiences, where we seek to focus and expose cultural and socially existing possibilities, and is therefore used in the exploratory research of unknown issues. It was intended, with the help of this form of approach, the generation of ideas and the aid of quantitative study, as well as in the final interpretation. Qualitative techniques of interview, direct observation, and engraving and focus groups were used for the present study. Focus group work was chosen based on the individual's tendency to form attitudes and points of view during their interactions, valuing intersubjective relations and exchanges of the students who will participate in the groups.

\section{Results and Discussion}

The curricular timetable for Mental Health in most medical schools in Brazil is not satisfactory to promote a broad debate and reflective approach of the most important points for medical training. In an attempt to broaden this contact, using new approaches and diversified methodologies, students unite to create academic leagues in the area of mental health, hoping to fill the gap of spaces with a different look for mental health. However, some leagues end up restricting the field of action to simple expository classes, without interaction between participants, limited to the figure of a speaker, who talks about a pre-established fear, little adding to the practical experience and the exchange of experiences, perceptions and construction of knowledge above barriers and ideas socially and historically constructed by common sense.

The expansion and foundation of mental health and psychiatry alloys are essential in the process of changing the negative view of concepts in mental health, but it has impact and strength when it encompasses the university tripod of research, teaching and extension, placing the medical student in contact with psychiatric patients in diverse environments, with a proposal of experiencing prevalent problems and the development of activities to prevent and promote the mental health of the community and the medical student [16].

The study of psychiatry during the medical internship in certain colleges aims at enabling the academic of the student medical course with concepts of mental health and psychiatric disorders prevalent in the Brazilian population, besides enabling the development of interdisciplinary and community practices in mental health, seeking a dissociation of traditional hospital-centered psychiatry models. It is essential the development of skills and abilities, as well as a greater understanding of concepts in mental health that allow an approach and treatment of a patient with mental disorder, with a generalist approach, avoiding the under diagnosis and the devaluation of the need of differentiated approaches for certain patients of psychiatry $[17,18]$.

Dynamic resources can be used within disciplines and extracurricular spaces in psychiatry within medical training, such as the use of music, body expressiveness, exploration of the classroom space, reading letters, audiovisual resources, among others, aiming raise awareness and lead to a greater reflection on concepts and themes in mental health. Experiences with the use of diverse, active and participative methodologies help in the discussion and sedimentation of concepts in mental health, resulting in contributions to the formation of future general practitioners with a holistic approach of the psychiatric patient, free of negative perceptions and stereotypes. The approach through differentiated methodologies of the traditional teaching model can be a way for an effective transformation of the gaze in mental health [19].

New theories underlying learning processes involve an ongoing transformation in the area of medical education and mental health. Such theories are linked to different understandings of active and dynamic teaching methodologies, including social, ethical and political aspects, giving the subject a more active participation in a debate where the student becomes a key player in the reflection and modification of the reality of health mental in a critical and conscious way. The passive and unidirectional transmission of scientific knowledge in the field of mental health is gradually replaced by a dialectical and broad construction of the reality in which the psychiatric patient and mental health in general are inserted $[20,21]$.

\section{Focal Groups Analysis}

During the second phase of the project, 26 students were interviewed, who participated in heterogeneous focus groups, according to the period of the medical course they were part of. The discussions were transcribed with an analysis of the content and activities carried out with subsequent categorization into 6 thematic groups. At the end of the focus groups, only the first period students were asked to design the idea of a psychiatric hospital nowadays and a patient with a specific mental disorder.

The data analyzed within the subject groups were separated into analytical categories and subdivided into topics, from the transcripts carried out during focus group activities. The student statements were not identified, each student being portrayed, taking the floor during the discussion as $\mathrm{E}$ and a subsequent numbering relative to the students' response order, E1 is the student who first answered the question, E2 the second student to respond, following such reasoning in a successive way, thus preserving the identity of the academic.

The first question to be raised during the focus group was related to the thematic group, axis Feelings Faced with Contact 
with the Psychiatric Patient. The first group consisted only of students in the 1st period of the medical course, which took place after the first tests of the course.

The second question of the focus group falls within the Vision axis of Psychiatry and Mental Health Care.

At the end of the focus groups, a drawing workshop was held with the participation of 40 students from the 1st period of the medical course, where each student was responsible for drawing on a blank sheet the idea that he possessed of a psychiatric hospital nowadays. The vast majority of students used images similar to those represented in the focus groups, in the students' testimonies of the 1st, 6th and 9th period, a closed environment, full of windows and bars, containing patients often tied and gagged. A minimal amount of students designed small representations of a hospital in the midst of nature, with the presence of some drawings of patients painting outside the hospital. Others wrote names of mental disorders around and some wrote names of drugs. Subsequently some students were asked to perform a description of the image they had represented on paper. At a last moment, each student drew his idea of a patient with a specific mental disorder, where they were represented patients with bipolar disorder, schizophrenia and depression. Most of the designs of patients with bipolar disorder externalized the idea of common sense about the disease, in an exhaustively repetitive pattern of two people's drawings, one looking happy and one looking sad. Between the two drawings was an arrow with a phrase that showed the patient's mood change seconds later. Some of the schizophrenic patients represented had aggressive facial features that sometimes were also described in words around the drawing, showing something similar to workshops and work done in other educational institutions, described in the literature, strengthening the idea that medical education still possesses a range of challenges to be faced for the construction of a generalist free of ideas historically imposed by traditional psychiatry and socially addicted with presences of stereotypes and stigmatizing images.

\section{Conclusion}

Anxieties, fear, fear and feeling of impotence generate suffering and intrinsic reflections in front of a patient's care with mental disorder, especially when dealing with a medical student. However, this delicate subject is still little approached within medical education, and there is a great lack of the curricular preparation of health professionals for the approach of patients in psychic suffering, mainly in the university, between medical students and teachers. As an initial focus, greater support and training of educators and preceptors is required, as well as the encouragement of debates and the challenge of confronting the achievement of the Psychiatric Reform within medical education, conveying the future benefits of this differentiated formation by shaping a a future doctor who is capable and willing to respond to demands and to perform a dignified and quality service, far from stereotypes and stigmatizing.
The students identify the need for a better preparation in relation to the approach of these patients, which should be carried out primarily by the university, later and in a complementary way, being able to be approached in debates with student organizations, student conversations wheels and through lectures to be held by academic leagues. However, they emphasize the need for pedagogical and work support with the students of all periods of the medical school in relation to the maintenance of the mental health of the students, identifying that the medical course is a facilitator of the development of mild or serious mental disorders, depend on the personality of the individual and the context of internal, family and academic pressures where they are inserted.

\section{References}

1. Martinhago F, Oliveira WF (2015) (De) Institutionalization: the perception of Psychosocial Care Enter professionals in Santa Catarina, Brazil. Health Soc 24: 1273-1284.

2. Lieberman JA, Ogas O (2016) Psychiatry: An Untold Story. 1st Ed. Sao Paulo: WMF Martins Fontes.

3. Almeida $A B$, Nascimento ERP, Rodrigues J, Zeferino MT, Souza AlJ, et al. (2015) Mobile Emergency Medical Services in the Psychological Crisis and the Psychosocial Paradig. Texto contextenferm 24: 1035-1043.

4. Silva AA, Terra MG, Leite MT, Freitas FF, Xavier MS, et al. (2015) Nursing and self-care in the world of psychiatric care. J Res Fundam Care 7: 2011-2020.

5. Almeida AB, Nascimento ERP, Rodrigues J, Schweitzer G (2014) Intervention in situations of psychic crisis: challenges and suggestions of a prehospital care staff. Rev Bras Enferm 67: 708-714.

6. Tavares CMM, Cortez EA, Muniz MP (2014) Care in the psychiatric hospital from the point of view of the nursing team. Rev Rene 15: 282-290.

7. Machado MP, Pereira MAO (2013) Perception of mental illness by health professionals: possibilities for extending care. Stud Res Psychol 13: 125-138.

8. Lima DU, Garcia APRF, Toledo VP (2013) Understanding the nursing team in schizophrenic patient care. Rev Rene 14: 503-511.

9. Goncalves MV (2013) The perception of CAPS professionals in the city of Rio de Janeiro on the attention to cases of attempted suicide in the elderly. Rio de Janeiro: Sergio Arouca National School of Public Health, Brazil.

10. Calgaro A, Souza EN (2009) Nurses' perception about care practice in out-of-hospital mental health services. Rev Gaucha Enferm 30: 476- 483.

11. Moraes M (2008) Integral healthcare model for treating problems caused by alcohol and other drugs: perceptions of users, their companions and practitioners. Cien Saude Colet 13: 121-133.

12. Paiva IL, Yamamoto $\mathrm{OH}$ (2007) In defense of the psychiatric reform: for a tomorrow that will be born without asking permission. Hist Sci Health-Manguinhos 14: 549-569.

13. Ramos-Cerqueira ATA, Torres AR, Martins STF, Lima MCP (2009) A stranger at my door: preparing medical students for home visits. Braz J Med Educ 33: 276-281. 
14. Botti NCL, Cotta EM, Celio FA (2006) Visit to the museum of madness: a learning experience on psychiatric reform. Rev Eletr Enf 8: 52-57.

15. Barros S, Aranha e Silva AL, Lopergolo ACD, Pitta AMF (1999) Innovative efforts in teaching practice and assistance in mental health-I. Rev Esc Enf 33: 192-199.

16. Goncalves RJ, Ferreira EAL, Gonçalves GG, Lima MCP, RamosCerqueira ATA, et al. (2009) Who "ties" to the psyche in medical school? The experience of the League of Mental Health of FMB Unesp. Braz J Med Educ abril-junho; 33(2):298-306.

17. Paulin LFRS, Pocas RCG (2009) The experience of Universidade Sao Francisco with the medical internship in psychiatry using the problem-based learning method. Rev Psychiatrist 31: 67-72.

18. Cyrino EG, Toralles-Pereira ML (2004) Working with teachinglearning strategies for discovery in the health area: problematization and problem-based learning. Cad Saude Publica 20: 780-788.

19. Soares AN, Silveira BV, Santos FBO, Alves PNM, Lana FCF (2013) (Re) meaning the care spaces in mental health: experience report. Text Context Nurs 22: 1214-1222.

20. Gomes MPC, Abrahao AL, Azevedo FFM, Louzada RCR (2013) Training and qualification: a study on the educational dynamics in mental health teams in Rio de Janeiro, Brazil. Interface (Botucatu).17: 835-845.

21. Silva JCB, Filho PO (2013) Discursive productions about the teamwork in the context of psychiatric reform: a study of workers in Psychosocial Care Centers. Psychol Stud 30: 609-617. 